\title{
Improving Reading Comprehension for Students with ADHD
}

\author{
Clayton E. Keller ${ }^{1} \&$ Hadeel H. Abuelhassan ${ }^{1 *}$ \\ ${ }^{1}$ College of Education, Doha, Qatar \\ *Hadeel H. Abuelhassan, E-mail: ha082519@qu.edu.qa
}

\begin{abstract}
Students with Attention Deficits Hyperactive Disorder (ADHD) have difficulties in reading comprehension. This paper reviews literature on how deficits in three types of attention (coming to attention, selective attention, and sustain attention) affect reading comprehension. In addition, the paper reviews three strategies for reading comprehension that follow Self-Regulation Strategy Development (SRSD) model (RQ,TWA, and TWA-WS). The strategies are designed for students with $A D H D$. The paper argues that TWA is more effective than RQ because it helps students with ADHD use the three types of attention more effectively while reading. Finally, the paper calls for more research that examine the effect of TWA strategy using SRSD model in the Arab world. This is because students who speak Arabic as a first language are different from students who speak English as a first language in terms of the structure of the two languages (i.e., there are two versions of Arabic: Dialect and Standard).
\end{abstract}

\section{Keywords}

$A D H D$, types of attention, reading comprehension, SRSD model, dialect Arabic, standard Arabic

Reading is essential not only in school academic learning, but also to lifelong learning (Duffy \& Roehler, 1989). In order to be able to read, people need to go through the process of decoding written words and comprehend them. This requires different cognitive processes including: perception, attention, and memory. The process of decoding requires changing symbols or letters into meaning through perception, which is the ability to match sensory information with information stored in memory (Zentall et al., 2012). On the other hand, comprehension requires building a mental representations, which involves the ability to recognize and recall main ideas and supporting details (Mason et al., 2011). In order to construct this mental representation, attention is needed. Attention allows people to focus or direct their cognitive function on a specific stimulus in order to process it. Deficits in attention entails deficits in recalling and storing information in memory (Raymond, 2011).

There are different types of attention. Most frameworks focus on three types: coming to attention, selective attention, and sustain attention (Conte, 1991; Keogh \& Margolis, 1976). All of these three components involve identifying relevant information and blocking irrelevant information (Klorman, 1991; Krupski, 1981). 
Coming to attention is when people prepare themselves to attend something. It is also called alertness since people become alert to a specific stimulus. Selective attention is when people select a relevant stimulus and ignore irrelevant stimuli (Zentall, 2005). This type of attention requires decision making function since people make decisions of what is relevant and ignore what is irrelevant. It also involves focusing on a stimulus until other cognitive processes such as memory and perception use it and give it meaning. After that, sustain attention takes over (Raymod, 2011). The function of sustain attention is to continually monitoring a relevant stimulus in addition to evaluating and rejecting stimuli that are not relevant for a specific task (Zentall, 2005). Sustain attention is essential for reading comprehension because readers need to maintain their attention on texts in order to comprehend them.

Students with Attention Deficits Hyperactive Disorder (ADHD) face difficulties in controlling attention. Some studies like Richards and colleagues in 1990 observed that students with ADHD seemed to have more difficulties with sustain attention, whereas those with learning disabilities have problems with selective attention. Other studies show that students with ADHD also have difficulties in selective attention since they get distracted easily or select irrelevant stimuli (Tsal et al., 2005). These deficits in different types of attention make students with ADHD have difficulties in reading comprehension. For example students with ADHD may read an entire passage without understanding it (Levine, 1987), as a result, they often have to repeat reading the same paragraph or take long time in order to grasp meaning (Robin, 1998). As Brock and Knapp reported in 1996, students with ADHD scored significantly lower on all measures of reading comprehension when compared with their nondisabled peers.

There are some medications to improve attention in students with ADHD. However, it is important to use medication combined with behavioral interventions in order to maintain the effect for longer periods (Miranda et al., 2006). One of the effective behavioral intervention model for students with ADHD is Self-Regulation Strategies Development (SRSD). This model was developed by Graham, Harris and colleagues to teach students with learning disabilities strategies for writing. However, it can be used in other areas as well such as reading and mathematics. The reason it can be applied to many areas is because it does not consist of fixed steps that need to be followed like a cooking book. Instead, it provides general format and guidelines that are flexible to students' various needs (Harris, et al., 2003).

SRSD has six stages: developing active background knowledge for a specific strategy, discussing the strategy, modeling it, making students memorize it, supporting it, and help students to independently performing it. For example:

1) In the stage of developing background knowledge, teachers develop any pre-skill knowledge, such as vocabulary or concepts that help in learning the strategy.

2) In the discussing stage, teachers and students discuss the strategy. Also, in this stage, the importance of student efforts should be emphasized in order to increase motivation and develop positive attribution to the strategy.

3) In the modeling stage, the teacher model the strategy and types of self- instructions. Type of self- 
instruction includes problem definition (i.e., what is it I have to do here?), focusing attention and planning (i.e., I have to concentrate, first, I need to...then...), self- evaluation and error correcting (i.e., have I used all my parts?), self- reinforcement (i.e., I like this ending).

4) In the memorizing stage, students are supported to memorize the strategy. They are told that if they cannot memorize it, they will not be able to use it.

5) In the stage of independent performance, students are supported to practice the strategy using scaffolding. Scaffolding is supporting the students until they master a skill.

6) Students need to independently practice the strategy.

These stages can be helpful to students with ADHD because it improves their attention and help them monitor and regulate themselves. For example, developing a prior knowledge help students with ADHD in coming to attention since prior knowledge would make them more alert to relevant stimulus or relevant information. In addition, the strategy helps students with ADHD to self- monitor and selfcheck whether they are doing what they are supposed to do. This helps them in maintaining their attention in a specific task. For example, students with ADHD might write a plan or a check- list for the steps needed to complete a task and then check whether they are following the plan or the list.

Most of studies about SRSD focused on writing. However, there are also studies about the effect of SRSD in reading (Harris et al., 2003). Some of the strategies for reading that use SRSD model are RQ, TWA, and TWA-WS. The first strategy requires asking Reciprocal Questions (RQ or ReQuest) in order to comprehend reading. The second strategy requires students to think before reading, think while reading, and think after reading (TWA). The third strategy uses TWA with written summarization.

Mason 2004 compared the effect of RQ and TWA intervention on both students with disabilities and students without disabilities. The sample in the study was 32 fifth grade students. All of them have low reading comprehension abilities. Furthermore, two of the 32 students have ADHD.

RQ strategy requires students to make questions about what they read. It was first developed by Manzo in 1969 to help students from age 7 to 26 year comprehend reading better. There are several steps to it:

- First teachers and students silently read the passage.

- Then, the teacher closes his or her book.

- Following this, student ask this teacher questions and the teacher answers.

- After that, students close their books and the teacher ask them questions.

However, RQ was used in a slightly different way in Mason 2004 study. Precisely, it was modified and taught using SRSD model. In addition, the main focus was teaching students techniques for developing good comprehension questions. Hence, the purpose is to teach students how to ask good questions instead of what questions you should ask. Teaching students how instead of what will lead to generalization of the techniques in other contexts.

In order to teach students the modified RQ method, the study followed the same six stages of SRSD model that was discussed earlier. For example, Students were introduced to question chart that provides examples of good questions. In addition, they were supported to model, memorize and practice the Published by SCHOLINK INC. 
strategy until they could learn to independently create good questions.

The other intervention was TWA. Similarly to RQ, TWA was taught using the same six stages of SRSD. However, TWA differ than RQ in the number of steps. There are nine steps for TWA. The first three steps happen prior to reading. Students need to think about the following: What is the author's purpose? What do I know about this topic? What do I want to know about this topic? The next three steps happen while reading. They are: Think about their reading speed (i.e., some parts of the text need to be read faster than other parts). Think about linking knowledge together. Think about rereading some parts of the text. The last three steps happen after reading. They are: Recalling the main idea, summarizing information and finally remembering what read. Figure 1 shows TWA taken from Mason 2004.
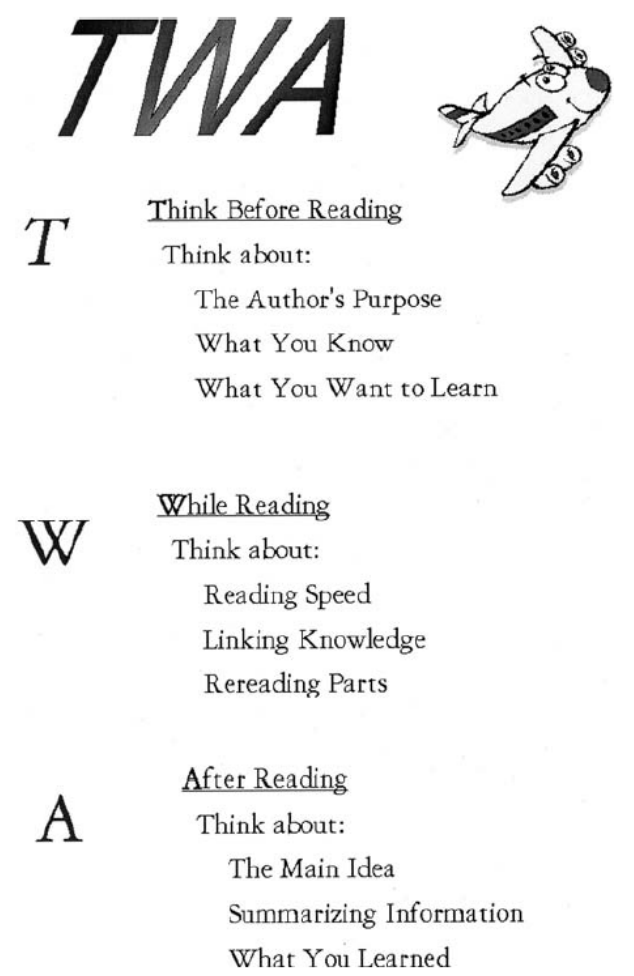

Figure 1. TWA Intervention (from Mason 2004)

Results of the study showed that TWA is more effective in improving reading comprehension when assessed using oral assessment in two tests (posttest and maintenance). For example, TWA group was significantly better than RQ group in telling the main idea, make oral summarization and retell what they read. In addition, TWA group did better in maintenance tests. However, in written assessments, self-efficiency, intrinsic motivation and social validity no difference was found between RQ and TWA. The study did not discuss why TWA is more effective than RQ. Nevertheless, reasons can be attributed to attention types that were discussed earlier. Hence, TWA appears to be more effective than RQ in improving coming to attention and selective attention. This is due to the three questions prior to reading in TWA model (What is the author purpose? What do you know? What do you want to know?). These 
questions help students to be more alert and thus able to use their selective attention more efficiently. On the other hand, RQ does not make students as alert to coming information because the questions are constructed during or after reading.

Besides coming to attention and selective attention, both RQ and TWA seem to be effective in sustaining attention while reading passages. This is because they follow SRSD model which allows students to observe their behavior and self- check whether they are concentrating and following the steps of RQ or TWA. Yet, TWA is more effective in sustaining attention. Speaking more specifically, it helps students process the information they read because by linking it during reading, recognizing the main idea and supporting details, they will be able to build larger images for mental representations. RQ seems less effective in this regard because its main focus is asking and answering single questions instead of focusing on building larger images of texts.

Since students with ADHD have deficits in their attention and reading comprehension, TWA should improve them. Mason 2004 study did not give evidences for the effect of TWA on students with ADHD. Even though the study involved two students with ADHD, data were not separated. Thus, it was not possible to examine the effect of TWA on students with ADHD. For this reason, Mason and colleagues conducted another study in 2011 to test the effect of TWA on students with ADHD. The study focused on the role of TWA in improving the number of main ideas and details recalled. The reason why the study focused on recalling is because attention problem cause problems in working memory (Raymond, 2011). Working memory is important in reading comprehension because it keeps information in the mind for a period long enough for the cognition to process them. In reading comprehension, working memory store information and link it to each other in order to make sense of it. Students with ADHD have reported to forget what they read at the top of the page by the time they come to the end (Barkley, 2006).

Mason 2011 examined the effect of TWA on three high school students with ADHD (14 to 15 year old). All of the three students are diagnosed with ADHD and scored low scores in reading comprehension tests. The procedures used to instruct and assess these students were similar to Mason 2004.

Results showed that TWA taught using SRSD model can improve reading comprehension for high school students with ADHD. All of the three students in the study showed improvement in the posttest and maintenance. For example, in the pretest, the number of main idea and supporting details in which students were able to recall ranged from zero to one. After the instructions, they were able to recall four to five main idea and supporting details. In addition, they gave a good feedback regarding the strategy.

One of the limitation of TWA strategy is that students are not able to transfer their comprehension in writing. For example, Mason 2004 study found that the written assessments for reading comprehension did not provide accurate reflection of what students learned from TWA since there was a discrepancy between their performance in the oral retell and their performance written retell. Possible reasons in which the study suggests is that students who struggle with reading often have insufficient writing, limiting their ability to express content in written form. Additionally, students who struggle with 
writing often have negative connotations for written assignments when compared to oral tasks. Motivation may have been depressed during the written retell. For these reasons, writing about reading comprehension requires different SRSD instruction.

In order to improve writing about reading comprehension, Rogevich and Perin in 2008 adopted Mason's TWA strategy and added written summarization to it. The participants were 63 male participants (13 to 16 year) with emotional and behavioral disorders (EBD), including 31 with ADHD.

Results indicated that participants with EBD showed large gains from TWA-WS strategy, including students with ADHD. At first, researchers hypothesized that participants with ADHD will show less gains. However, the results proved that the presence of ADHD did not reduce gains from the intervention, but it interferes with the participants' abilities to apply newly learned skills to different tasks, and their ability to hold the skills they learned over time. For example, participants with ADHD performed lower in the far and near transfer tests in addition to maintenance. But, their performance in posttest was equal to their peers. A possible explanation is that posttest depends on memorization, while near and far transfer require additional cognitive processes that require more attention.

Overall, TWA is an effective technique in helping students with ADHD improving their reading comprehension. There is a need to examine whether these techniques would be as effective for students with ADHD in the Arab world. This is because students who speak Arabic as a first language are different from students who speak English as a first language in terms of text comprehension since there are different versions or Arabic language: the dialect and the standard. The dialect is the mother tongue or the native language in which Arabs use in their everyday life. On the other hand, the standard Arabic is the formal language in which Arabs learn in school. These two versions can be significantly different in terms of phonemic awareness, vocabulary, and sentence structures. Thus, learning the language of schools in the Arab world is similar to learning a second language (Data for Education Programming in Asia and Middle East, 2014). Since school texts are written in standard Arabic, this might negatively affect the reading comprehension of students with ADHD.

Arab scholars have examined different techniques to help students with learning disabilities in reading comprehension such as: RQ, key word method, discussion, and summarization (Al Sartawi, 1999; Esaa, 2007). Although these methods proved to be effective for students with learning disabilities, they might not be as effective for students with ADHD because they do not teach self- regulation techniques in which students with ADHD need. Therefore, there is a need to examine the effect of TWA using SRSD on reading comprehension for students with ADHD in the Arab world.

\section{References}

Barkley, R. A., Fischer, M., Smallish, L., \& Fletcher, K. (2006). Young adult outcome of hyperactive children: Adaptive functioning in major life activities. Journal of the American Academy of Child \& Adolescent Psychiatry, 45(2), 192-202.

Boyle, H., Ajjawi, S., \& Xiang, Y. (2014). Task Order 15: Data for Education Programming in Asia 
and Middle East. Florida: International is a trade name of Research Triangle Institute.

Brock, S., \& Knapp, P. (1996). Reading comprehension abilities of children with attention deficit/hyperactivity disorder. Journal of Attention Disorders, 1, 173-186.

Conte, R. (1991). Attention disorders. Learning about learning disabilities, 60-103.

Duffy, G. G., \& Roehler, L. R. (1989). Improving classroom reading instruction: A decision-making approach (2nd ed.). New York: Random House.

Esaa, M. M. (2007). The effect of reciprocal teaching on reading comprehension for students with learning disabilities in grade five. Scientific Journal, 23(1), 340-383.

Harris, K. R., Graham, S., \& Mason, L. H. (2003). Self-regulated strategy development in the classroom: Part of a balanced approach to writing instruction for students with disabilities. Focus on Exceptional Children, 35, 1-17.

Johnson, J. W. Reid, R., \& Mason, L. H., (2011). Improving the reading recall of high school students with ADHD. Remedial and Special Education.

Keogh, B. K., \& Margolis, J. (1976). Learn to labor and to wait Attentional problems of children with learning disorders. Journal of Learning Disabilities, 9(5), 276-286.

Klorman, R. (1991). Cognitive event-related potentials in attention deficit disorder. Journal of Learning Disabilities, 24(3), 130-140.

Krupski, A. (1981). An interactional approach to the study of attention problems in children with learning handicaps. Exceptional Education Quarterly.

Lienemann, T. O., \& Reid, R. (2008). Using self-regulated strategy development to improve expository writing with students with attention deficit hyperactivity disorder. Exceptional Children, 74, 471-486.

Manzo, A. V. (1969). The request procedure. Journal of Reading, 13, 123-126, 163.

Mason, L. H. (2004). Explicit Self-Regulated Strategy Development Versus Reciprocal Questioning: Effects on Expository Reading Comprehension Among Struggling Readers. Journal of Educational Psychology, 96(2), 283.

Miranda, A., Jarque, S., \& Tárraga, R. (2006). Interventions in school settings for students with ADHD. Exceptionality, 14(1), 35-52.

Nielsen, M., Subiaul, F., Galef, B., Zentall, T., \& Whiten, A. (2012). Social learning in humans and nonhuman animals: Theoretical and empirical dissections. Journal of Comparative Psychology, 126(2), 109.

Raymond, E. B., \& DeCourcey, C. M. (2011). Learners with mild disabilities: A characteristics approach. Pearson/A and B.

Richards, G. P., Samuels, S. J., Turnure, J. E., \& Ysseldyke, J. E. (1990). Sustained and selective attention in children with learning disabilities. Journal of Learning Disabilities, 23(2), 129-136.

Robin, A. (1998). ADHD in adolescents: Diagnosis and treatment. New York: Guilford Press.

Rogevich, M. E., \& Perin, D. (2008). Effects on science summarization of a reading comprehension Published by SCHOLINK INC. 
intervention for adolescents with behavior and attention disorders. Exceptional Children, 74(2), 135-154.

Sartawi, A. M. (1999). The effect of reading comprehension methods in improving reading comprehension for students with learning disabilities. Journal of King Saud, 11(2), 165-175.

Tsal, Y., Shalev, L., \& Mevorach, C. (2005). The diversity of attention deficits in ADHD the prevalence of four cognitive factors in ADHD versus controls. Journal of Learning Disabilities, 38(2), 142-157.

Zentall, S. S. (2005). Theory-and evidence-based strategies for children with attentional problems. Psychology in the Schools, 42(8), 821-836. 